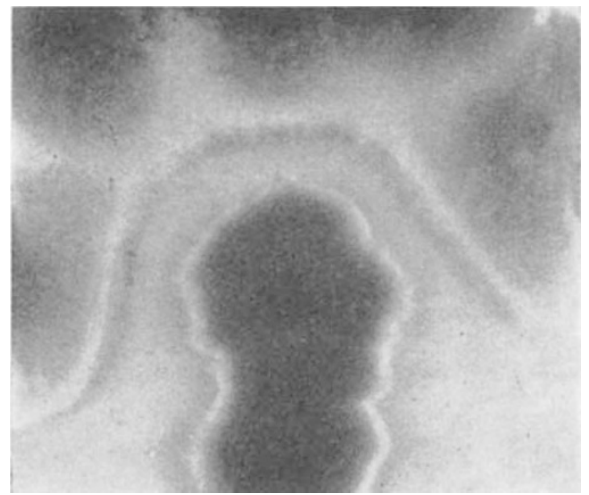

Fig. 1. Antagonistic effect of Alternaria tenuis (centre culture) on Boletus scaber in a synthetic medium; eight weeks from inoculation. (Part of a culture flask photographed from the reverse side)

1,000 c.c.) in the following order of degree : Boletus granulatus, $B$. variegatus markedly inhibited; $B$. bovinus, Rhizopogon luteolus-inhibited ; B. scabermildly inhibited. The accompanying photograph demonstrates the condition of $B$. scaber eight weeks from inoculation.

Dr. P. W. Brian, who tested the effect of culture filtrates of a strain of A. tenuis under observation on three mycorrhizal fungi, was able to confirm the results obtained in mixed cultures. $\mathrm{He}$ recorded $B$. scaber to be less inhibited than $B$. bovinus and Rhizopogon luteolus (B. variegatus and B. granulatus were not tested against the culture filtrates).

Pseudomycorrhizal fungi, that is, forms of Mycelium radicis atrovirens and Rhizoctonia-like mycelia, did not show any effects from $A$. tenuis in mixed cultures on the nutrient medium referred to above and on a number of other media employed, including cornsteep.

The reactions of the mycorrhizal mycelia to $A$. tenuis seem to represent a parallel phenomenon to the effects induced by species of Penicillium as described by Brian', who reported a differential susceptibility of mycorrhizal fungi to gliotoxin produced by a Penicillium species active in the heathland soil of Wareham (Dorset). B. bovinus, observed by Brian to be less affected than the other ectotrophic fungi tested, is the only mycorrhiza-former of forest trees which is initially present in this particular heathland soil ${ }^{2}$. It is of interest that $B$. scaber, found to be least inhibited by the fungistatic properties of A. tenuis, has been successfully inoculated, on various occasions, into nursery soils of the arable type in which other mycorrhizal mycelia, more markedly affected by $A$. tenuis, fail to grow. In this connexion it is also noteworthy that pseudomycorrhiza-formers, recorded to be unaffected by $A$. tenuis, are generally abundant in the soils under consideration and, if not present initially, may easily be introduced.

Since there is no experimental evidence (as yet) that the reactions of the root-fungi to $A$. tenuis in the natural soil are similar to those observed on synthetic media, it seems too early to suggest that the fungistatic property of $A$. tenuis may be responsible, at least in part, for the absence of certain mycorrhizal activities under field conditions. However, one feels tempted not to dismiss the attractive hypothesis of a possible relationship between the antagonistic behaviour of $A$. tenuis to mycorrhizaformers and the poor growth of young trees which, in the soils under observation, is invariably accompanied by a lack of true mycorrhizal associations and, at the same time, by a noticeable profusion of pseudomycorrhizal infections. Experiments designed to analyse certain factors involved in this hypothetical relationship are in progress.

Bedford College,

IDA LEVISOHN

University of London,

Regent's Park,

London, N.W.1.

March 1.

${ }^{1}$ Brian, P. W., Nature, 155, 637 (1945).

${ }^{2}$ Rayner, M. O., Nature, 156, 174 (1945).

\section{Tomato Grafting Experiments at Tihany}

THE results of our grafting experiments made on the $F_{1}$ generation of the tomato varieties Golden Apple and Oxheart were published in 1951. These experiments resulted in definite genetical changes ${ }^{1}$. Further results were handed over during a visit to Hungary to Anne McLaren and Donald Michie, and they were published in Nature ${ }^{2}$. I sent Dr. A. J. Bateman samples from our material, at his request, for genetical control. The results of his investigation were communicated to $\mathrm{me}$ in personal letters also published in Nature ${ }^{3}$.

The changes we had observed were of two kinds : (1) changes of sexual hybrid character, with segregation in the progenies, and (2) mutation-like changes without segregation. Plants belonging to the first group are, according to Bateman's results, presumably sex-hybrids, and the changes we had observed ${ }^{1}$ referred to quantitative characters. Leaving aside Prof. J. B. S. Haldane's explanation that the inheritance of characters may be attributable to virus transduction, I can only explain the occurrence of these sex-hybrids as due to lack of care. In that summer there were in the greenhouse many tiny insects, including thrips, and the simple isolation with cotton must have been insufficient. It is also possible that, under the influence of the stock, crossfertilization could have happened more easily ('vegetative approximation').

In the cases of non-segregating types, Baternan ${ }^{3}$ refers also to the possibility that these are the results of grafting. I cannot accept the supposition that the Oxheart material originally used was polymorph. Both varieties had been regularly inbred by us since 1946, and neither spontaneous cross-fertilization nor mutation-like changes had been observed. I must also emphasize the fact that these non-segregating types have no practical importance.

I. am vory grateful to my English colleagues for their interest, and especially to Dr. A. J. Bateman for his criticisms and the exact genetical evaluation by which he demonstrated the correct interpretation of our work.

Department of Botany,

Biological Research Institute of

Hungarian Academy of Science,

Tihany Lake Balaton.

$$
\text { Feb. } 2 .
$$

1 Velföldy, L. J. M., Acta Biol. Acad. Sci. Hung., 2, 3 (1951).

2 McLaren, Anne, and Michie, D., Nature, 174, 390 (1954).

${ }^{3}$ Bateman, A. J., Nature, 175, 1118 (1955).

- Haldane, J. B. S., New Biol., 19, 7 (1955). 